Proceedings

Elsevier Editorial System(tm) for NIMB

Manuscript Draft

Manuscript Number: NIMB_PROCEEDINGS-D-16-00124R1

Title: Identification and imaging of modern paints using Secondary Ion Mass spectrometry with $\mathrm{MeV}$ ions

Article Type: SI: NIMB_ECAART12

Section/Category: SI: NIMB_ECAART12

Keywords: MeV-SIMS; synthetic organic pigments; modern paints; heavy ion microprobe; molecular imaging

Corresponding Author: Dr. Iva Bogdanovic Radovic, PhD

Corresponding Author's Institution: Ruđer Bošković Institute

First Author: Iva Bogdanović Radović, PhD

Order of Authors: Iva Bogdanović Radović, PhD; Zdravko Siketić, PhD; Dubravka Jembrih-Simbürger, PhD; Nikola Marković, BSc; Marta Anghelone, BSc; Valentin Stoytschew, BSc; Milko Jakšić, PhD

Manuscript Region of Origin: CROATIA

Abstract: Secondary Ion Mass Spectrometry using MeV ion excitation was applied to analyse modern paint materials containing synthetic organic pigments and binders. It was demonstrated that synthetic organic pigments and binder components with molecular masses in the $\mathrm{m} / \mathrm{z}$ range from 1 to 1200 could be identified in different paint samples with a high efficiency and in a single measurement. Different ways of mounting of mostly insulating paint samples were tested prior to the analysis in order to achieve the highest possible yield of pigment main molecular ions. As Time-of-Flight mass spectrometer for MeV Secondary Ion Mass Spectrometry is attached to the heavy ion microprobe, molecular imaging on cross-sections of small paint fragments was performed using focused ions. Due to the fact that molecules are extracted from the uppermost layer of the sample and to avoid surface contamination, the paint samples were not embedded in the resin as is usually done when imaging of paint samples using different techniques in the field of cultural heritage. 


\title{
Identification and imaging of modern paints using Secondary Ion Mass Spectrometry with MeV ions
}

\author{
Iva Bogdanović Radović ${ }^{\mathrm{a} *}$, Zdravko Siketića ${ }^{\mathrm{a}}$, Dubravka Jembrih-Simbürger ${ }^{\mathrm{b}}$, Nikola Marković ${ }^{\mathrm{a}+}$, \\ Marta Anghelone ${ }^{\mathrm{b}}$, Valentin Stoytschew ${ }^{\mathrm{a}}$, Milko Jakšić ${ }^{\mathrm{a}}$ \\ ${ }^{\text {a} L a b o r a t o r y ~ f o r ~ I o n ~ B e a m ~ I n t e r a c t i o n s, ~ R u đ e r ~ B o s ̌ k o v i c ́ ~ I n s t i t u t e, ~ B i j e n i c ̌ k a ~ 54, ~ H R-10000 ~ Z a g r e b, ~ C r o a t i a ~}$ \\ ${ }^{\mathrm{b}}$ Institute of Science and Technology in Art, Academy of Fine Arts Vienna, Schillerplatz 3, 1010 Vienna, Austria \\ +Present address: Center for Nuclear Technologies, Technical University of Denmark, Ris $\varnothing$ Campus, DK-4000 \\ Roskilde, Denmark. \\ * Corresponding author e-mail: iva @irb.hr
}

\begin{abstract}
Secondary Ion Mass Spectrometry using MeV ion excitation was applied to analyse modern paint materials containing synthetic organic pigments and binders. It was demonstrated that synthetic organic pigments and binder components with molecular masses in the $\mathrm{m} / \mathrm{z}$ range from 1 to 1200 could be identified in different paint samples with a high efficiency and in a single measurement. Different ways of mounting of mostly insulating paint samples were tested prior to the analysis in order to achieve the highest possible yield of pigment main molecular ions. As Time-of-Flight mass spectrometer for MeV Secondary Ion Mass Spectrometry is attached to the heavy ion microprobe, molecular imaging on cross-sections of small paint fragments was performed using focused ions. Due to the fact that molecules are extracted from the uppermost layer of the sample and to avoid surface contamination, the paint samples were not embedded in
\end{abstract}


the resin as is usually done when imaging of paint samples using different techniques in the field of cultural heritage.

Keywords: MeV-SIMS, synthetic organic pigments, modern paints, heavy ion microprobe, molecular imaging

\section{Introduction}

Due to the development of the modern industry in the $20^{\text {th }}$ century a large variety of Synthetic Organic Pigments (SOPs) and polymers was produced. Some of the polymers started to be used as new binding media by the artists in the modern and contemporary art [1]. Nowadays synthetic organic polymers are widely used binding media in artistic object, especially acrylic, vinyl and alkyds. Whereas a huge amount of research is continuously focused on the investigations of art objects from the earlier centuries, some researchers have moved recently their interest toward studying of art works from the second half of the $20^{\text {th }}$ century. Those studies are important to gain information about the durability, usability and stability of modern paint materials [2].

Ion Beam Analysis (IBA) techniques are often used for studying cultural heritage objects [3-5] and among them Particle Induced X-ray Emission (PIXE) has been established as the most often used one [6-8]. However, PIXE, as well as the standard IBA techniques do not give any information about the molecular composition of the sample, which is important to distinguish among different SOPs showing very similar molecular structures and polymers used as binders in the modern paint materials. SOPs are typically studied with methods like Gas Chromatography Mass Spectrometry (GC/MS), Pyrolysis-GC/MS, Fourier Transform Infrared (FTIR) spectroscopy, Raman spectroscopy, Nuclear Magnetic Resonance (NMR), etc. [9-15]. Although GC/MS and Py-GC/MS are the most important analytical techniques for routine analysis of organic materials, both methods are based on separation of the mixture compounds before their 
identification with MS. In the case that polar compounds have to be identified even a chemical derivatization of the sample has to be done before the analysis [16,17]. FTIR and Raman spectroscopy that are today widely used for the identification of chemical compounds in artworks mainly due to the possibility of using portable instruments [18] are limited in determination of components in complex mixtures due to the overlapping bands in the measured spectra or due to the low concentrations of SOPs in the paints. Thus, sometimes only the class of the material can be identified and not the exact molecular composition itself. Time-of-flight Secondary Ion Mass Spectrometry with keV ions (keV-ToF-SIMS) [19] is established in the cultural heritage for many years. It specifies the organic or inorganic surface composition with high spatial and mass resolution and has already been applied to the analysis of paints containing oil or tempera binders and traditional pigments [20-24]. Inspired by the progress of its keV energy primary ion counterpart, heavy $\mathrm{MeV}$ ion desorption [25,26] came back into the focus this time under a new name - MeV-SIMS [27-30]. The main difference between the two methods comes from the different interaction mechanism that $\mathrm{keV}$ and $\mathrm{MeV}$ ions have with the sample surface. In case of keV-SIMS, secondary molecular ions are ejected from the sample surface due to the dominant nuclear sputtering (collision cascade), while ejection of secondary molecular ions with $\mathrm{MeV}$ primary ions is a consequence of electronic sputtering mechanism that dominates the $\mathrm{MeV}$ ion energy deposition process and causes desorption of intact large secondary molecular ions. Several orders of magnitude larger yields as well as less fragmentation are expected for larger molecular masses when $\mathrm{MeV}$ ions are used for the excitation [30].

Here we will demonstrate that the SIMS technique that employs MeV heavy ion excitation can be a method of choice for the identification of SOPs used in modern art objects. In the present work MeV-SIMS was applied for the identification of SOPs in the surface layer of the paints as well as for molecular imaging of pigments in the layered paint samples (non-embedded paint 
cross-sections). In order to show that very good results can be achieved even for the identification of very similar SOPs in the paints, paints containing characteristic phthalocyanine pigments such as copper phthalocyanine blue, Pigment Blue PB15:1 and PB15:3 (two different polymorphs), metal-free phthalocyanine PB16, and chlorinated copper phthalocyanine green Pigment Green PG7 were selected. To show the influence of different methods of mounting on the MeV-SIMS spectra, the red paint containing a red organic pigment belonging to the Naphthol AS class, Pigment Red PR112 is chosen.

\section{Experimental}

All measurements were performed in a high vacuum $\left(10^{-6}-10^{-7}\right.$ mbar) using MeV-SIMS setup with a Time-of-Flight (TOF) spectrometer at the RBI heavy ion microprobe, which is described in detail in Tadić et al. [31]. For the analysis of paint materials, focused 5 and $8 \mathrm{MeV}$ Si ions were used. The typical beam lateral resolution was about $5 \times 5 \mu \mathrm{m}^{2}$. Beam was scanned over different sample areas (from $100 \times 100 \mu \mathrm{m}^{2}$ for the identification of pigments to $1200 \times 1200 \mu \mathrm{m}^{2}$ for the imaging of paint cross sections). The beam current in the pulsed mode was $\sim 0.2$ fA. Secondary molecular ions were steered towards the TOF by the $+5 \mathrm{kV}$ voltage applied to the sample holder. Multi-Stop TDC Data Acquisition System in the heavy ion deflection start mode was used with the $100 \mu$ s time between two heavy ion pulses (duration of $4 \mathrm{~ns}$ ). All experimental parameters and data acquisition were controlled with the SPECTOR software [31,32].

As this is the first application of the MeV-SIMS in the field of cultural heritage, the analyses were first carried out on the paints that were systematically prepared at the Institute of Science and Technology in Art, at the Academy of Fine Arts. For self-made paints different phthalocyanine blue (PB15:1, PB15:3 and PB16) phthalocyanine green (PG7) and Naphthol AS 


\section{Results and discussion}

\subsection{Different sample mountings}

As MeV-SIMS has not been applied before for the analysis of modern paint samples it was important to determine the best possible mounting procedure for the pigment/paint samples. According to the present instrument setup, positive secondary molecular ions were extracted from the sample kept at $+5 \mathrm{kV}$ using an acceleration potential difference between the sample surface and a grounded extractor. Therefore it was not possible to use directly pigments/paints casted on the insulating glass slides due to the fact that homogeneous extraction electric field as well as no sample charging cannot be ensured. First small paint fragments were put onto conductive carbon tape attached to the Si wafer. This way of mounting did not work well for all analysed paints with pigments from different pigment classes, especially for paints with red pigments where no high mass peaks were observed in the mass spectrum. A further problem found in the spectra collected from the samples mounted on the carbon tape was that in all spectra peaks characteristic for PDMS (polydimethylsiloxane) were detected. PDMS is a well-known surface contaminant coming from the carbon tape glue (which was clearly visible in the mass spectrum from $\mathrm{C}$ tape, not shown here). Therefore, another sample mounting procedure was used which consisted of pressing the very small sample fragment into the pure indium metal. First, pure indium $(99.9 \%$ Alpha Aesar indium shot, tear drop) was pressed to obtain flat surface and then a paint fragment was gently pushed into it with a help of a flat and clean aluminium plate. Using this method a good extraction field was ensured for the secondary molecular ions of all classes of pigments analysed and no PDMS contamination was present in the spectra.

Fig. 1 shows mass spectra of the same alkyd paint with PR112 (Naphthol AS, $[\mathrm{M}+\mathrm{H}]^{+}$at $\mathrm{m} / \mathrm{z}$ 484.0) mounted on the carbon tape (black) and on indium (red). From the figure it can be seen 
that for the sample mounted on indium the main peak at $\mathrm{m} / \mathrm{z} 484.0$ and the fragment ions at $\mathrm{m} / \mathrm{z}$ 378.0 and 106.1, which are characteristic for this pigment, are clearly seen compared to the sample fixed on the Si wafer with carbon tape where those peaks are not seen at all. The peaks at $\mathrm{m} / \mathrm{z} 105.0$ and 149.0 are fragments from the alkyd binder. Also for the sample mounted on C tape, PDMS peaks with m/z 147, 207, 221, 281 were detected which are not present in the case when the sample is mounted directly on In. This clearly indicates that handling and mounting of samples is crucial for extracting intact molecular ions from the sample surface.

\subsection{Identification of SOPs in paints}

In Fig.2 the MeV-SIMS spectra (m/z range between 100 and 700) for three different blue phthalocyanine pigments in alkyd paint were presented. PB16 is metal-free phthalocyanine showing the main molecular peak $[\mathrm{M}]^{+}$at $\mathrm{m} / \mathrm{z} 514.2$ and a fragment ion $\left[\mathrm{C}_{8} \mathrm{H}_{5} \mathrm{~N}_{2}\right]^{+}$at $\mathrm{m} / \mathrm{z} 129.0$ (black line). Both, PB15:3 and PB15:1 are copper containing ( $\mathrm{Cu}-\mathrm{Pc} ` s)$ phthalocyanine pigments, showing the main molecular peaks $[\mathrm{M}]^{+}$at $\mathrm{m} / \mathrm{z} 575.1$ (blue and red line). As PB15:1 is chlorine stabilized PB15 pigment which contains $0.5-1 \mathrm{Cl}$ atoms per molecule[1], PB15:1 has an additional" $[\mathrm{M}]^{+ \text {" }}$ at $\mathrm{m} / \mathrm{z} 609.0$ (molecule is containing $1 \mathrm{Cl}$ atom) compared to PB15:3. The mass difference between two peaks is 34 not 35 due to the fact that when molecule is containing $\mathrm{Cl}, 1$ $\mathrm{H}$ from the phthalocyanine ring is substituted by $\mathrm{Cl}$. This feature can be used to distinguish the PB15:3 from chlorine stabilized PB15:1. Learner [9] reported also the presence of chlorine stabilized blue Cu-phthtalocyanine in some artistic paints. Additionally, in both paints, phthalocyanine (Pc) fragment ion $\left[\mathrm{C}_{8} \mathrm{H}_{5} \mathrm{CuN}_{2}\right]^{+}$at m/z 192.0 (red line) belonging to PB15:3 and PB15:1 is clearly seen. 
The alkyd binder used in this study is an orthophthalic based alkyd, the polyalcohol part is pentaerythritol (not glycerol). This is confirmed by Py-GC/MS measurements of the samples reported here. Further peaks shown in the Fig.2 are corresponding to the protonated phthalic anhydride at m/z 149.0 and the fragment ion at m/z 105.0 resulting from the loss of $\mathrm{CO}_{2}$ from protonated phthalic anhydride, which is a mass signature of this alkyd binder type. This demonstrates that pigments as well as binder can be identified in a single spectrum in only one measurement. A great advantage of the MeV-SIMS over other mass spectrometry techniques used for the identification of SOPs in paints, such as Py-GC/MS, is that the molecular ion peak and larger fragment ions are obtained, enabling a straightforward identification without consuming or destroying the sample during analysis and without any chemical sample treatment step priory to the analysis. Thus samples still remain for analyses with complementary methods. As already mentioned, Raman and FTIR analyses with the possibility to be employed in a noninvasive way are often limited by paint matrix (e.g. paint mixtures, low pigment concentrations), making exact identification or distinguishing between PB15:3 and chlorinated PB15:1 pigments in paints not always possible.

As demonstrated in Fig.3, mass spectra for PG7 pigment powder, phthalocyanine green, with main molecular peak $[\mathrm{M}]^{+}$at $\mathrm{m} / \mathrm{z}$ 1127.2, (depending on chlorination, in this case it is fully chlorinated PG7 with $16 \mathrm{Cl}$ ) obtained using $5 \mathrm{MeV} \mathrm{Si}^{4+}$ ions, collection time $\mathrm{t}=173 \mathrm{~s}$ and ion current $\mathrm{I}=0.16 \mathrm{fA}$. Main molecular peak $[\mathrm{M}]^{+}$as well as several peaks corresponding to the lower numbers of $\mathrm{Cl}$ atoms per molecule can be clearly seen. This proves that pigments with masses above m/z 1000 can be also detected through main molecular peaks in short collection time and 
with very low ion currents which can be important when sample damage by ion beam should be avoided.

Summarised, the big advantages of the MeV-SIMS can be clearly pointed out: MeV-SIMS gives the exact identification of the synthetic organic pigments (SOPs) in paints. The alkyd binder is identified as well in the same spectrum, meaning in only one analysis. Usually, to get comparable information multi-analytical approach is used such as Raman spectroscopy, applied to identify SOPs, and FTIR for the identification of the binders in the paints. In many cases also additional Py-GC/MS or different MS based measurements (e.g. DTMS, Direct TemperatureResolved Mass spectrometry [33]) are necessary to provide exact identification of SOPs.

\subsection{Imaging of paint cross sections}

In many cases it is of great importance when analysing paint samples from art objects to see how the detected pigments and/or binders are distributed in different layers of the paint. This can give information about painting technology, which can further support dating of the objects or support the conservators in their work on objects.

To test ability of the method for molecular imaging in different paint layers, two-layered paint with two phthalocyanine blue pigments in alkyd binder was used (PB15:1 and PB15:3 containing paint on microscope glass slide). In Fig. 4 the sample is turned through 90 degrees, thus the PB15:1 containing paint is shown on the left side of the images, followed by the PB15:3 containing paint on the right). Mass $\mathrm{m} / \mathrm{z}$ at 575.1 as described earlier, which is characteristic peak for both, PB15:1 and PB15:3 is clearly distributed in both paint layers. The difference between this two pigments is due to peak at m/z at 609.0 attributed to $\mathrm{Cl}$ stabilized $\mathrm{PB} 15: 1$ and this peak is clearly present only in left layer, where PB15:1 is mixed with alkyd. Resulting maps are showing 
a) overlay of three signals coming from alkyd (red, m/z 105.0), PB15:1 and PB15:3 (blue, 575.1), and PB15:1 (green, m/z 609.0), b) m/z 105.0 (alkyd), c) m/z 575.1, and d) m/z 609.0. Total scanned area is $1.2 \times 1.1 \mathrm{~mm}^{2}$. For the measurements $8 \mathrm{MeV} \mathrm{Si}^{4+}$ ions were used (detection in positive ion mode).

The next example in Fig. 5 presents the application of MeV-SIMS for the identification of synthetic organic pigments in the real sample taken from the outdoor sculpture "Plavi cvijet" (2000). The sample shows dark blue colour and is analysed on the front side, which was exposed to the environmental conditions. As can be seen, the blue phthalocyanine pigment PB15:3 (m/z 575.1) and the weak signal from the pigment violet PV23 (m/z 589.5) was detected by MeVSIMS as well as the alkyd binder in the paint (peaks at $\mathrm{m} / \mathrm{z} 105$ and 149). It is important to mention that sample was not treated or cleaned in any way and therefore signals from both pigments PB15:3 and PV23 were probably weak due to fact that surface of the sample was exposed to the environmental conditions and that MeV SIMS is detecting molecules from the uppermost layer of the sample.

To confirm existence of both pigments PB15:3 and PV23 as well as to see their depth distribution, cross-section was prepared by cutting the sample by scalpel and fixing freshly prepared cross section between two In sheets without any polishing. Fig. 6 shows 2D maps of selected mass peaks obtained on cross section from the sample "Plavi cvijet". Surface of the sample is on the right side. Total scanned area was $175 \mu \mathrm{mx} 145 \mu \mathrm{m}$. For the measurements $8 \mathrm{MeV}$ $\mathrm{Si}^{4+}$ ions were used. Fig. 6 shows: a) overlay of three signals corresponding to alkyd (red), PB15:3 (blue) ,and PV23 (green), b) single map for alkyd m/z 105.0, c) single map for PB15:3 $\mathrm{m} / \mathrm{z}$ 575.1, and d) single map for PV23 m/z 589.5. As obtained in Fig. 6, both pigments are distributed in the whole analysed area of the dark blue paint layer and no layered structure was 
found. It seems that measured area on the right of the image is slightly richer in the binder, which is most probbably due to the inhomogeneous extraction field caused by the sample surface morphology (sample was not polished).

\section{Conclusions}

The present work describes the first application of the MeV-SIMS method for cultural heritage studies, namely for the identification of SOPs and binders in modern and contemporary paint. We have shown that different SOPs could be easily identified together with the alkyd binder in a single measurement. We have also demonstrated that with MeV-SIMS and a focused heavy ion beam, molecular imaging at the micrometer level can be achieved. Using molecular ions and large fragments of blue phthalocyanine pigments showing similar molecular structure can be quickly distinguished between each other in paint layers. Further, different SOPs were identified in a real sample from an outdoor sculpture, even though such samples usually show much more stronger ageing then paintings usually shown in museums.

MeV-SIMS presents very promising features important for the study of cultural heritage such as: high molecular yields for intact high mass secondary molecular ions obtained with currents three orders of magnitude lower than the ones used for other microprobe IBA techniques (important for valuable and sensitive cultural heritage samples) and short measurement time. Furthermore, this type of MeV-SIMS with a ToF spectrometer could be introduced at low cost in any heavy ion IBA setup. Thus, MeV-SIMS investigations of modern and contemporary paintings can be added as a new application field for accelerator based analytical techniques. 


\section{Acknowledgments}

This work is supported by the Unity through Knowledge Fund Contract no. 4/13, bilateral project between Croatia and Austria HR10/2014 and Croatian Center of Excellence for Advanced Materials and Sensing devices (CEMS). V.S. acknowledges support by Marie Curie Actions ITN as an Integrating Activity Supporting Postgraduate Research with Internships in Industry and Training Excellence (SPRITE) under EC contract no. 317169. We would like to thank Mag. Mirta Pavić from Museum of Contemporary Art in Zagreb, Croatia for providing us with real samples. We also gratefully acknowledge the support of the research by the Head of the Institute of the Science and Technology in Art, Academy of Fine Arts Vienna, Prof. Dr. Manfred Schreiner. 


\section{References}

[1] Willy Herbst, K. Hunger, Industrial Organic Pigments: production, properties, applications, Wiley-VCH, 2002.

[2] R.L. Feller, Accelerated ageing: photochemical and thermal aspects, The Getty Conservation Institute, Research in conservation, 1994.

[3] C. Jeynes, M.J. Bailey, N.J. Bright, M.E. Christopher, G.W. Grime, B.N. Jones, V.V. Palitsin, R.P. Webb, Nucl. Instr. and Meth. B 271 (2012) 107-118.

[4] L. Beck, L. de Viguerie, Ph. Walter, L. Pichon, P.C. Gutiérrez, J. Salomon, M. Menu, S. Sorieul, Nucl. Instr. and Meth. B 268 (2010) 2086-2091.

[5] A. Quaranta, J. Salomon, J.C. Dran, M. Tonezzer, G. Della Mea, Nucl. Instr. and Meth. B 254 (2007) 289-294.

[6] V. Corregidor, A.R. Oliveira, P.A. Rodrigues, L.C. Alves, Nucl. Instr. and Meth. B 348 (2015) 291-295.

[7] N. Grassi, Nucl. Instr. and Meth. B 267 (2009) 825-831.

[8] A. Denker, J. Opitz-Coutureau, Nucl. Instr. and Meth. B 213 (2004) 677-682.

[9] T.J.S. Learner, Analysis of modern paints, The Getty Conservation Institute, 2004.

[10] J. Russel, B.W. Singer, J.J. Perry, A. Bacon, Anal. Bioanal. Chem. 400 (2011) 1473-1491.

[11] E. Ghelardi, I. Degano, M.P. Colombini, J. Mazurek, M. Schilling, T. Learner, Anal. Bioanal. Chem. 407 (2015) 1415-1431.

[12] M. R. Derrick, D. Sulik, J. M. Landry, Infrared Spectroscopy in Conservation Science, The Getty Conservation Institute, 1999.

[13] M. Anghelone, D. Jembrih-Simbürger, M. Schreiner, Spectrochim. Acta A 149 (2015) 419425.

[14] J.J. Boon, F.G. Hoogland, J. van der Hoorst, Mass Sectrometry of Modern Paints. Modern Paints Uncovered, The Getty Conservation Institute, Los Angeles, 2007.

[15] J.J. Boon, T. Learner, J Anal. Appl. Pyrol. 64 (2002) 327-344.

[16] F. Capitelli, T.J.S. Learner, A. Cummings, Proceedings of the $13^{\text {th }}$ Triennial Meeting of the ICOM Committee for Conservation, Vol. 1, James \& James, London (2002) 231-237.

[17] F. Capitelli, J Anal. Appl. Pyrol. 71 (2004) 405-415.

[18] F. Rull-Perez (Ed.), H.G.M. Edwards, D.C. Smith, P. Vandenabeele (Co-editors), Selected Topics in Raman Spectroscopic Applications, Geology, Bio-materials, Art, Publidisa, Valladolid, 2007.

[19] J. C. Vickerman, D. Briggs, TOF-SIMS: Materials Analysis by Mass Spectrometry - 2nd Edition, IM Publications 2013.

[20] M. Dowsett, A. Adriaens, Nucl. Instr. and Meth. B 226 (2004) 38-52.

[21] K. Keune, F. Hoogland, J. Boon, D. Peggie and C. Higgitt, Int. J. Mass spectrom. 284 (2009) 22-34.

[22] A. Atrei, F. Benetti, E. Gliozzo, G. Perra, N. Marchettin, , Int. J. Mass spectrom. 369 (2014) $9-15$.

[23] B. Marino, Paints quantified Image analytical studies of preparatory grounds used by Van Gogh, PhD Thesis, University of Amsterdam, 2006.

[24] R. Van Ham, L. Van Vaeck, F. Adams and A. Adriaens, Anal. Bioanal. Chem. 383 (2005) 991-997.

[25] P. Håkansson, A. Johansson, I. Kamensky, B.Sundqvist, J. Fohlman, P. Peterson, IEEE T. Nucl. Sci., Vol. NS-30, No. 2. (1983). 
[26] H. Voit, H. Frohlich, P. Duck, B. Nees, E. Nieschler, W. Bischof, W. Tiereth, IEEE T. Nucl. Sci., Vol. NS-30, No. 2 (1983).

[27] T. Seki, Y. Wakamatsu, S. Nakagawa, T. Aoki, A. Ishihara, J. Matsuo, Nucl. Instr. and Meth. B 332 (2014) 326-329.

[28] H. Yamada, K. Ichiki, Y. Nakata, S. Ninomiya, T. Seki, T. Aoki, and J. Matsuo, Nucl. Instr. and Meth. B 268 (2010) 1736-1740.

[29] L. Jeromel, Z. Siketic, N.O. Potocnik, P. Vavpetic, Z. Rupnik, K. Bucar, P. Pelicon, Nucl. Instr. and Meth. B 332 (2014) 22-27.

[30] B.N. Jones J. Matsuo, Y. Nakata, H. Yamada, J. Watts, S. Hinder, V. Palitsin and R. Webbet al, Surf. Interface Anal. 43 (2011) 249-252.

[31] T. Tadić, I. Bogdanović Radović, Z. Siketić, D. D. Cosic, N. Skukan, M. Jakšić, J. Matsuo, Nucl. Instr. and Meth. B 332 (2014) 234-237.

[32] M. Bogovac, I. Bogdanović, S. Fazinić , M. Jakšić , L. Kukec, W. Wilhelm, Nucl. Instr. and Meth. B 89 (1994) 219-222.

[33] C.A. Menke, R. Rivenc, T. Learner, Int. J. Mass Spectrom. 284 (2009) 2-11. 
Figure Caption:

Fig. 1. Comparison of the MeV-SIMS mass spectra of the alkyd paint containing red pigment PR112 mounted on carbon tape (black) and pressed into indium (red). Both measurements were done using $5 \mathrm{MeV} \mathrm{Si}^{4+}$ ions in a positive ion mode.

Fig. 2. MeV-SIMS spectra of self-made paints containing different blue phthalocyanine pigments in the alkyd binder measured with $5 \mathrm{MeV} \mathrm{Si}^{4+}$, positive ion mode. Main molecular peaks of the metal-free (PB16, black line), metal-containing (PB15:3, blue line) and chlorine stabilized metalcontaining (PB15:1, red line) pigments are clearly separated. Alkyd binder is identified through peaks at $\mathrm{m} / \mathrm{z} 149.0$ and 105.0 .

Fig. 3. MeV-SIMS spectra for PG7 (phthalocyanine green) obtained using $5 \mathrm{MeV} \mathrm{Si}^{4+}$ ions in a positive ion mode, collection time $\mathrm{t}=173 \mathrm{~s}$ and ion current $\mathrm{I}=0.16 \mathrm{fA}$. Main molecular peak at $\mathrm{m} / \mathrm{z}$ 1127.2 as well as several peaks corresponding to the lower numbers of $\mathrm{Cl}$ atoms per molecule can be clearly seen.

Fig. 4. 2D-molecular maps taken on the cross-section of the alkyd paint containing PB15:1 (layer on the left side) painted over the layer of alkyd paint containing PB 15:3 (right side). a) Overlay of three signals coming from alkyd (red), PB15:1+PB15:3 (blue) and PB15:1 (green), b) m/z 105.0, c) $\mathrm{m} / \mathrm{z} 575.1$ and d) $\mathrm{m} / \mathrm{z}$ 609.0. Scan size is $1.2 \times 1.1 \mathrm{~mm}^{2}$.

Fig. 5. MeV-SIMS spectrum taken from the front side of the dark blue sample "Plavi cvijet" (2000). $5 \mathrm{MeV} \mathrm{Si}^{4+}$ ions, detection in positive ion mode.

Fig. 6. 2D-molecular maps of the cross-section of the sample "Plavi cvijet" (2000): a) overlay of alkyd signal (red), PB15:3 (blue), and PV23 (green), b) single map of alkyd signal, c) signal map of PB15:3 signal and d) single map of PV23 corresponding signal. Surface of the sample is on the 
right. Total scanned area is $175 \mu \mathrm{m}$ x $145 \mu \mathrm{m}$. For the measurements $8 \mathrm{MeV} \mathrm{Si}^{4+}$ ions were used, detection in positive ion mode. 


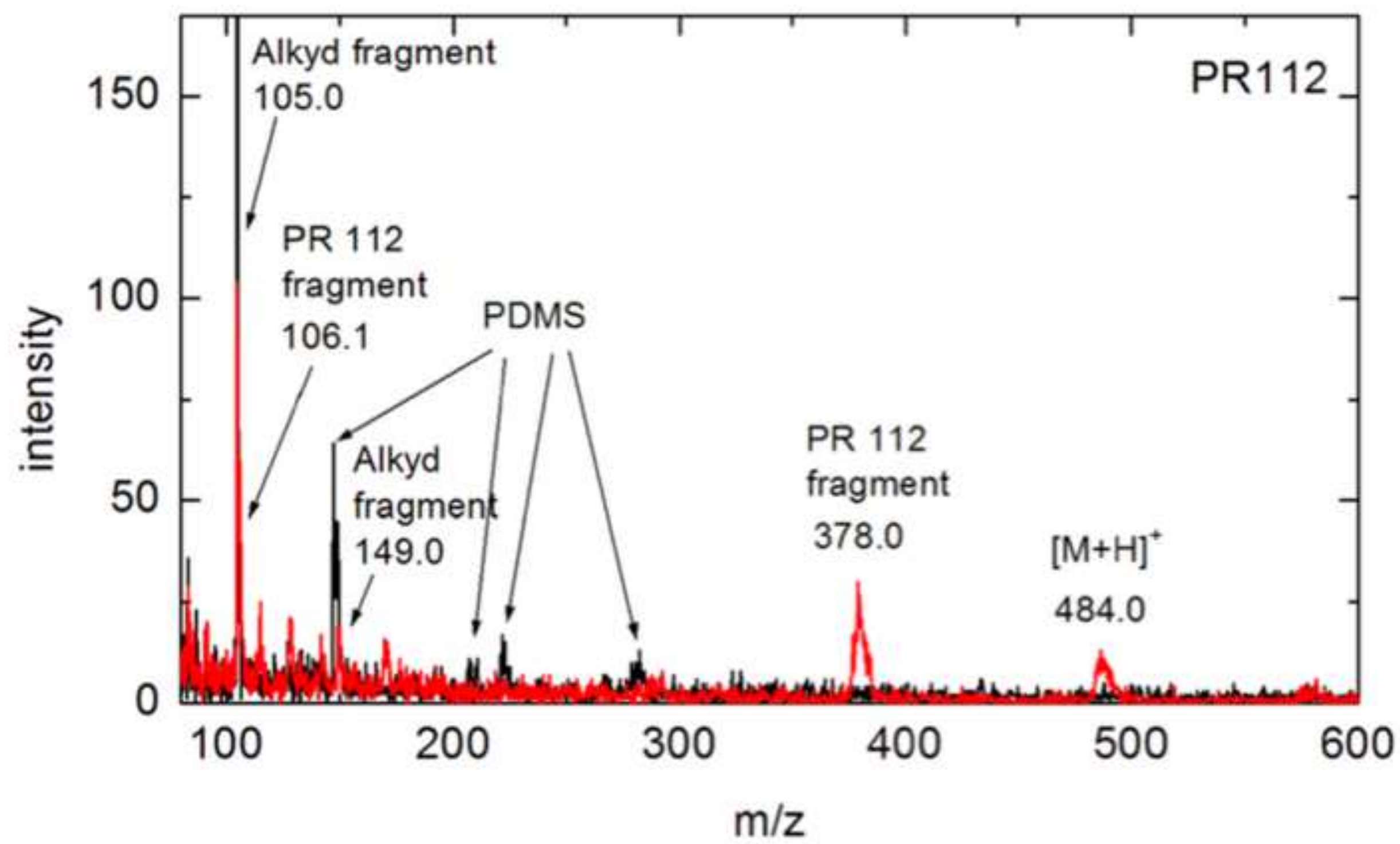




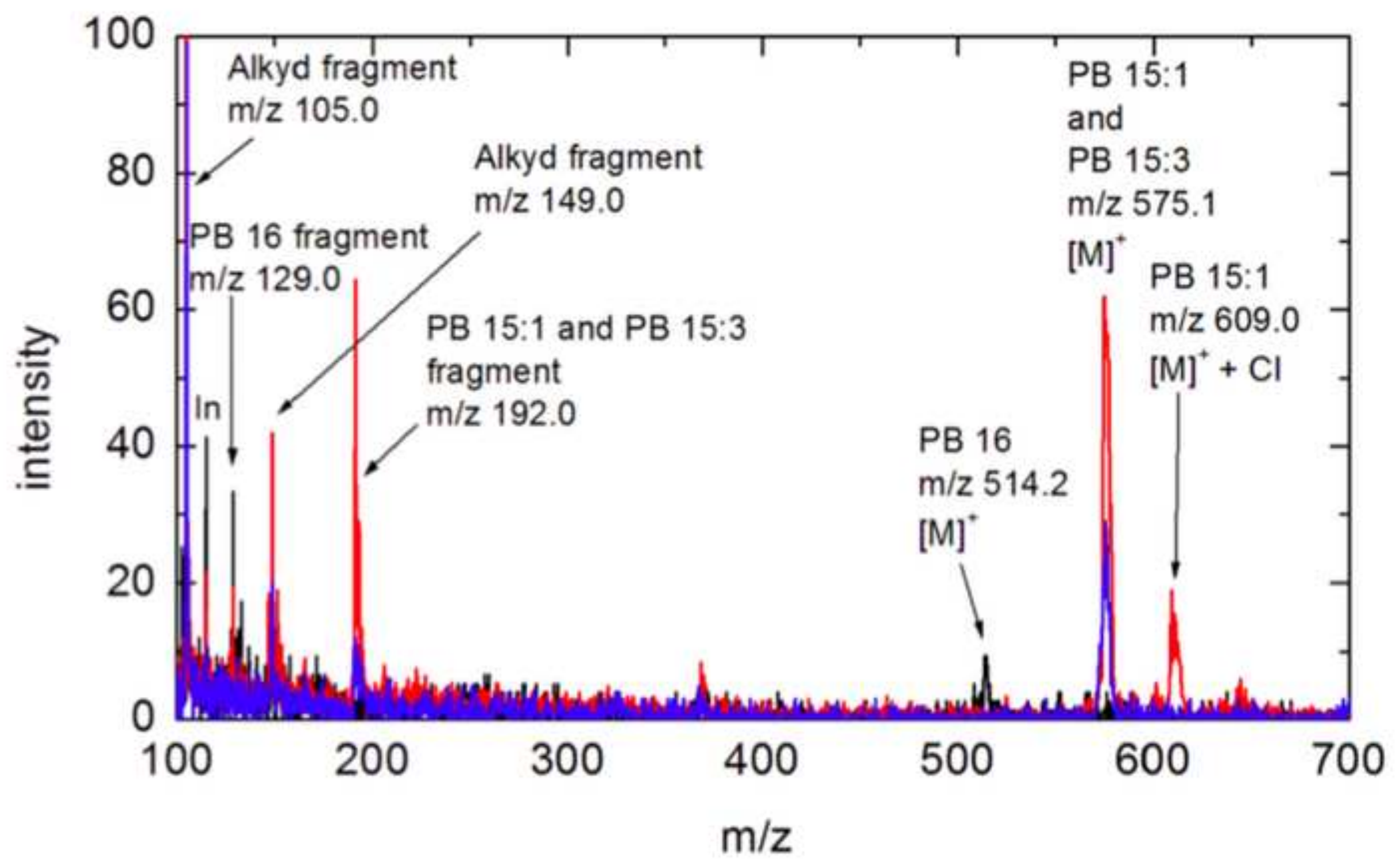




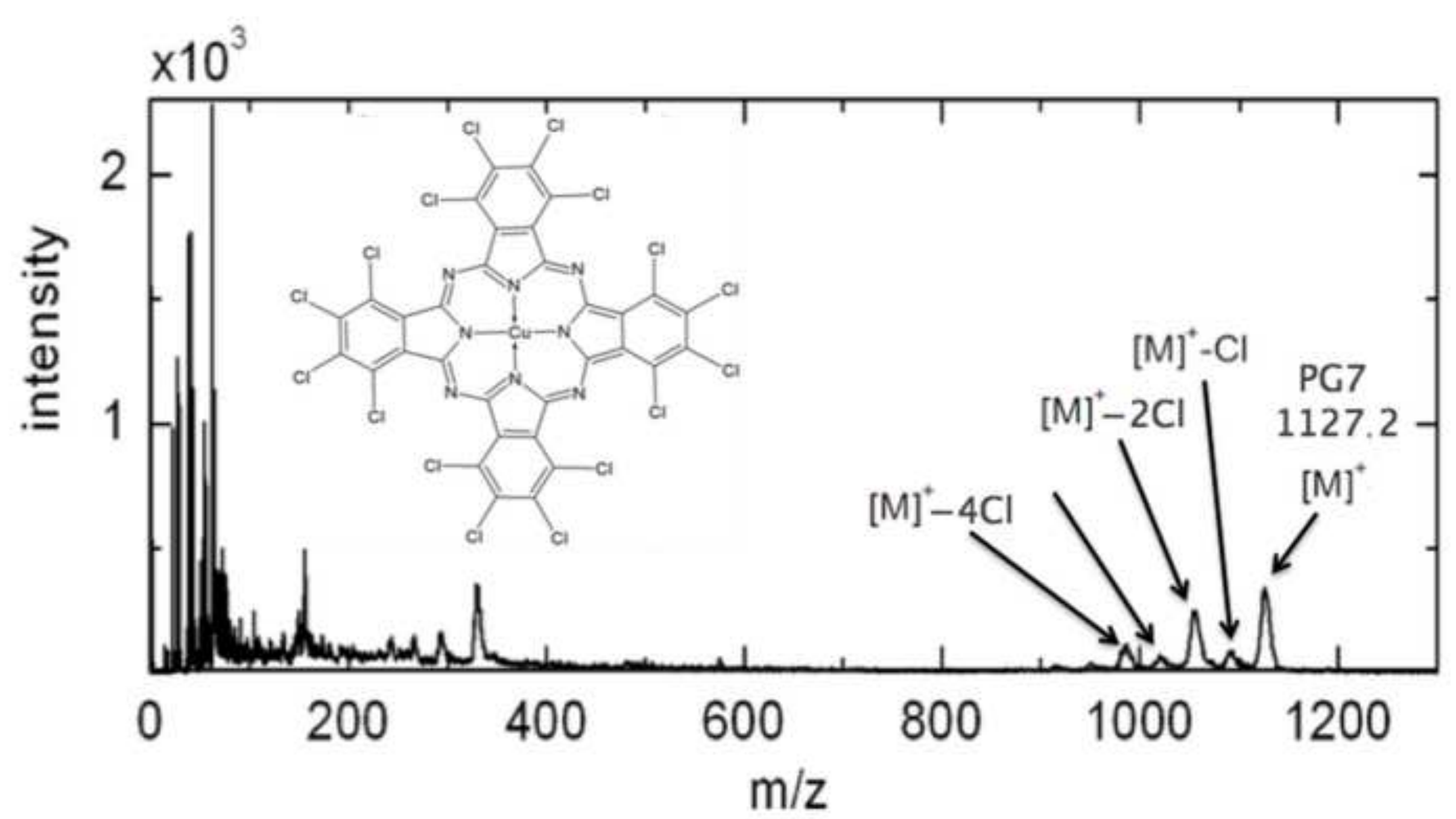

Click here to download high resolution image 
Figure
Click here to download high resolution image
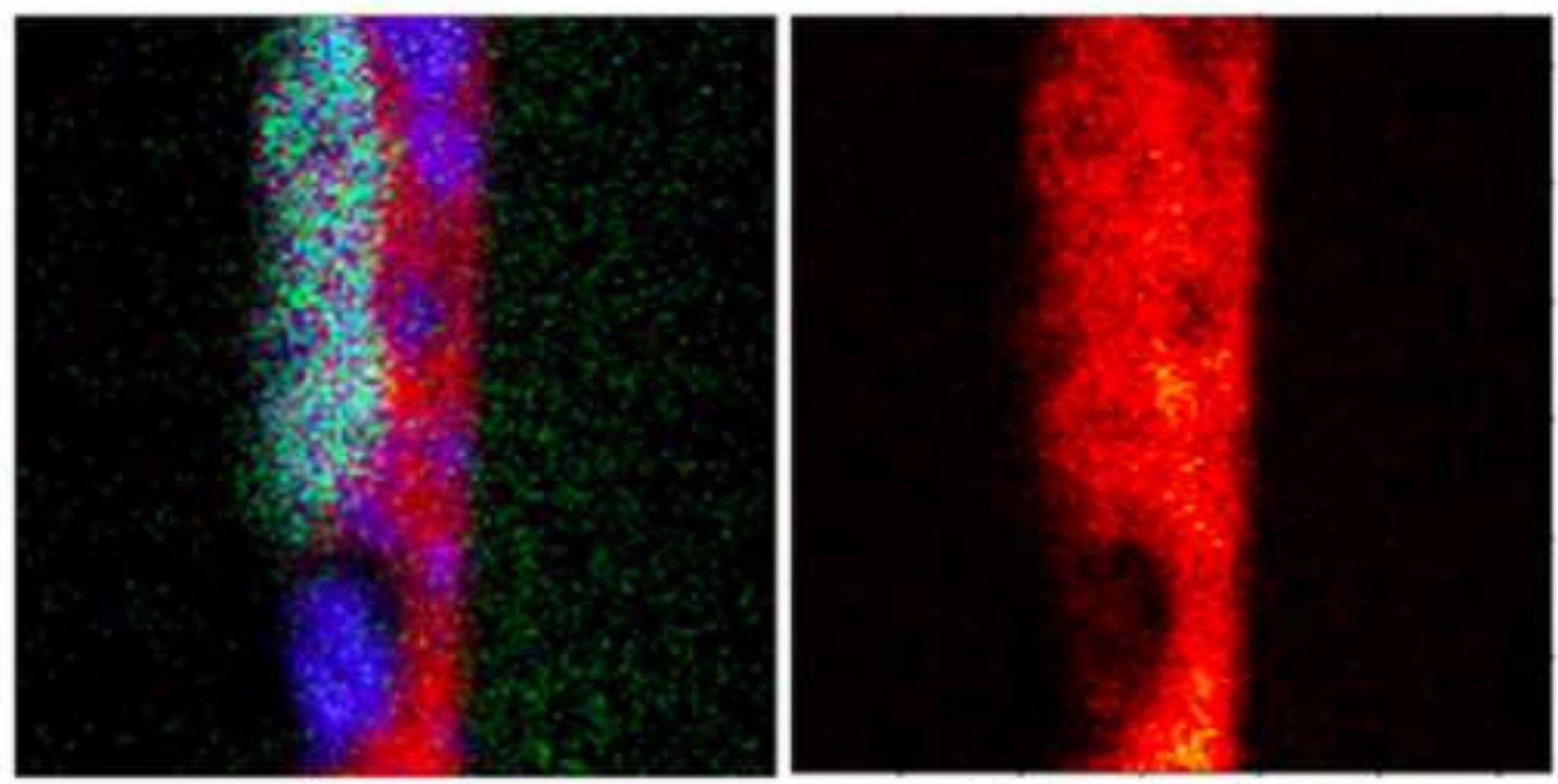

a) overlay

b) alkyd m/z 105

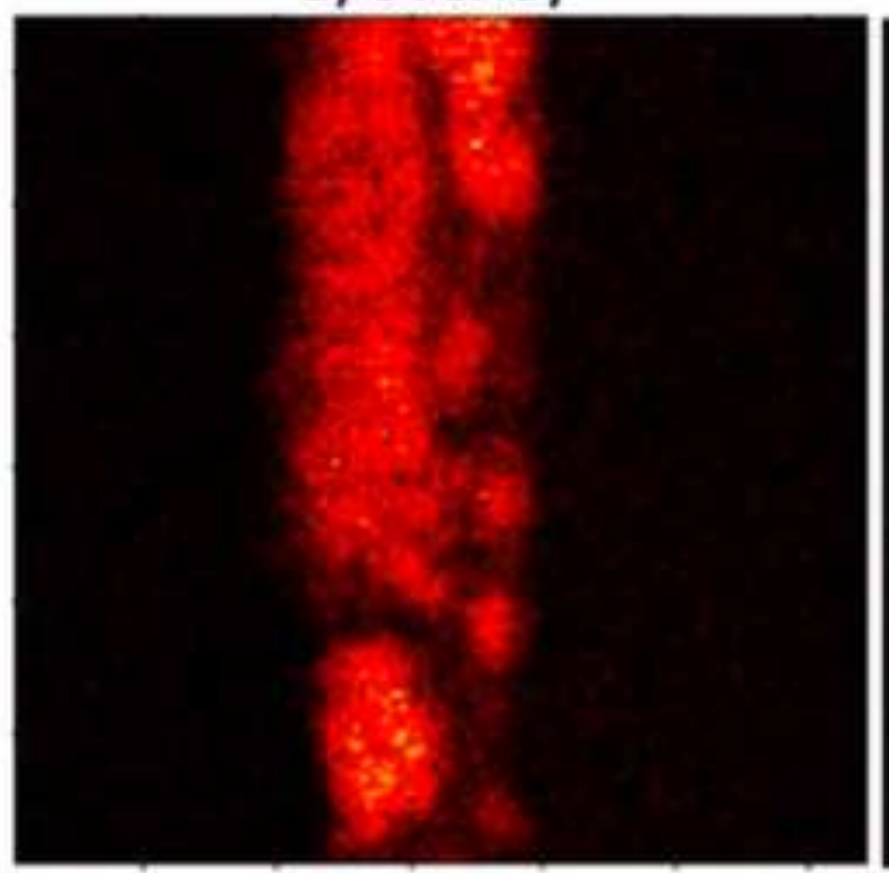

c) PB15:1+PB15:3 (m/z 575.1)

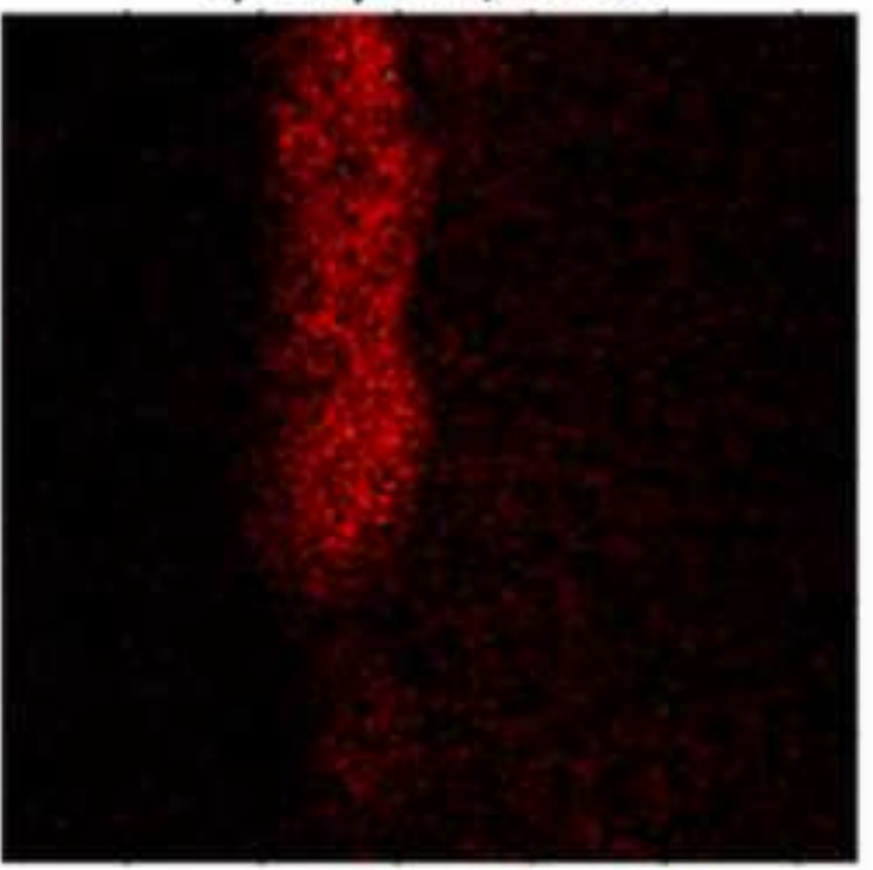

d) PB15:1 (m/z 609.0)

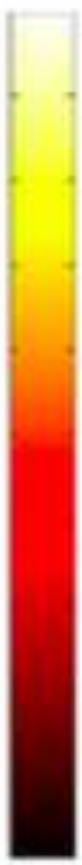



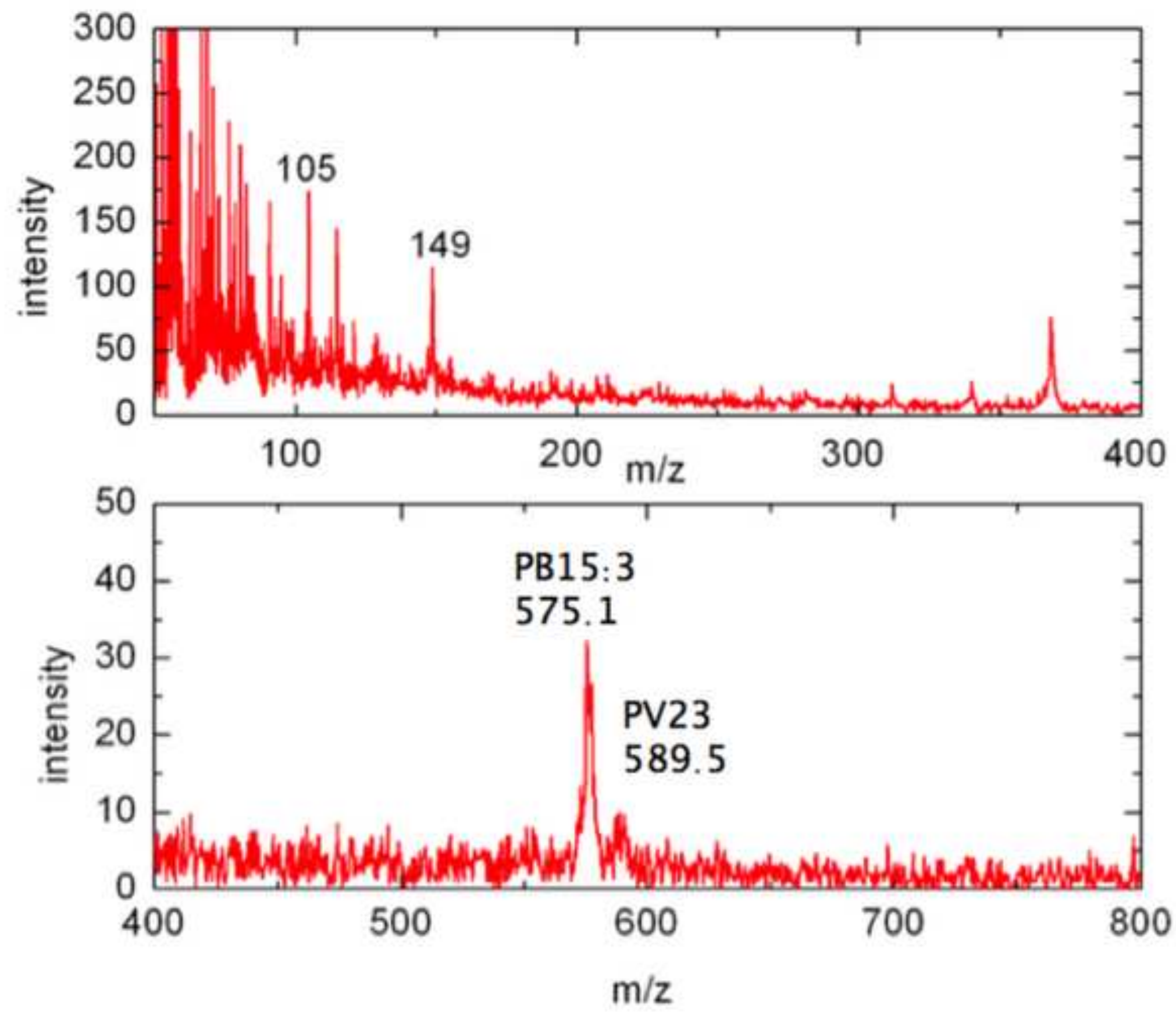
Figure
Click here to download high resolution image
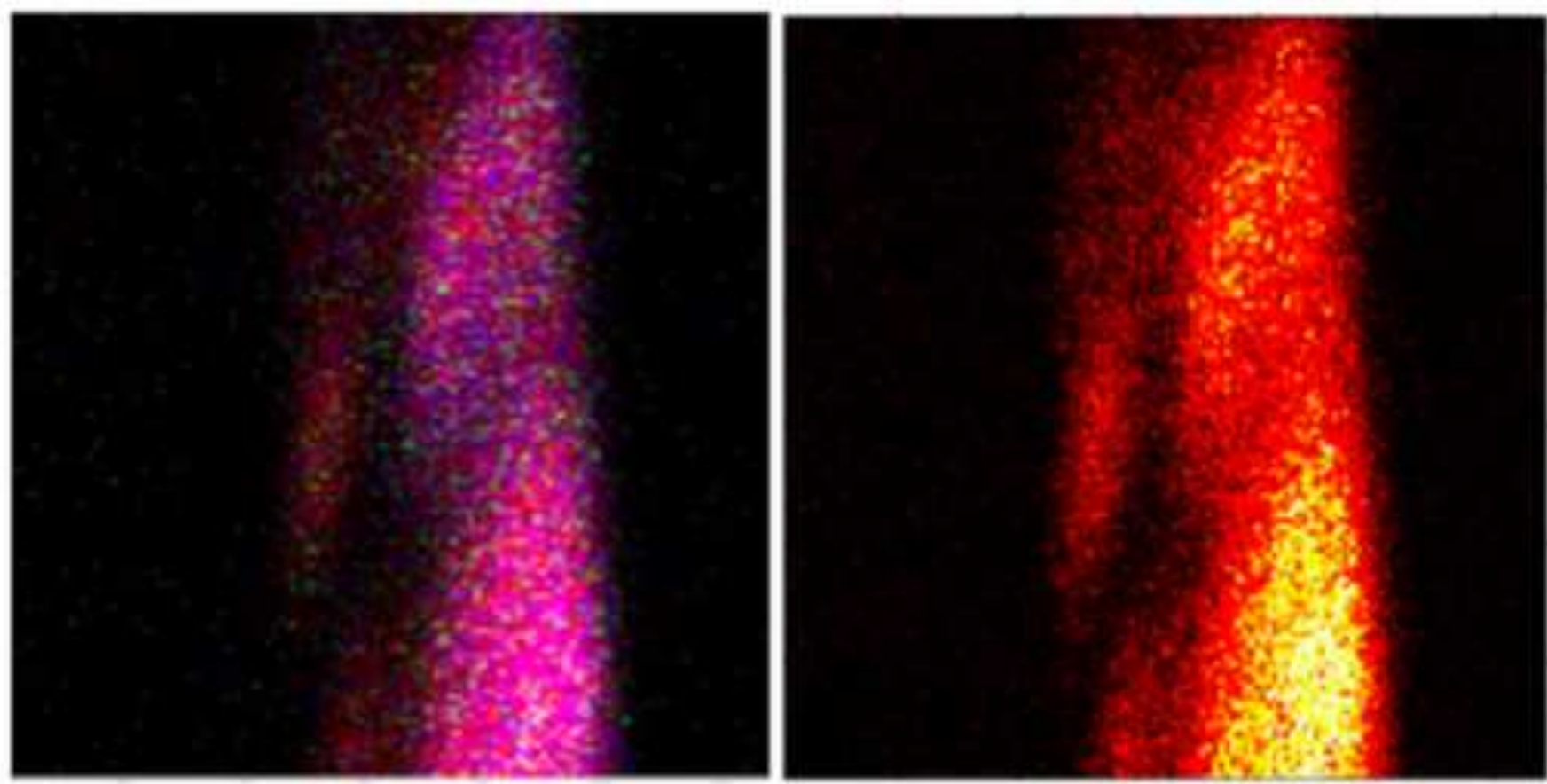

a) overlay

b) alkyd m/z 105
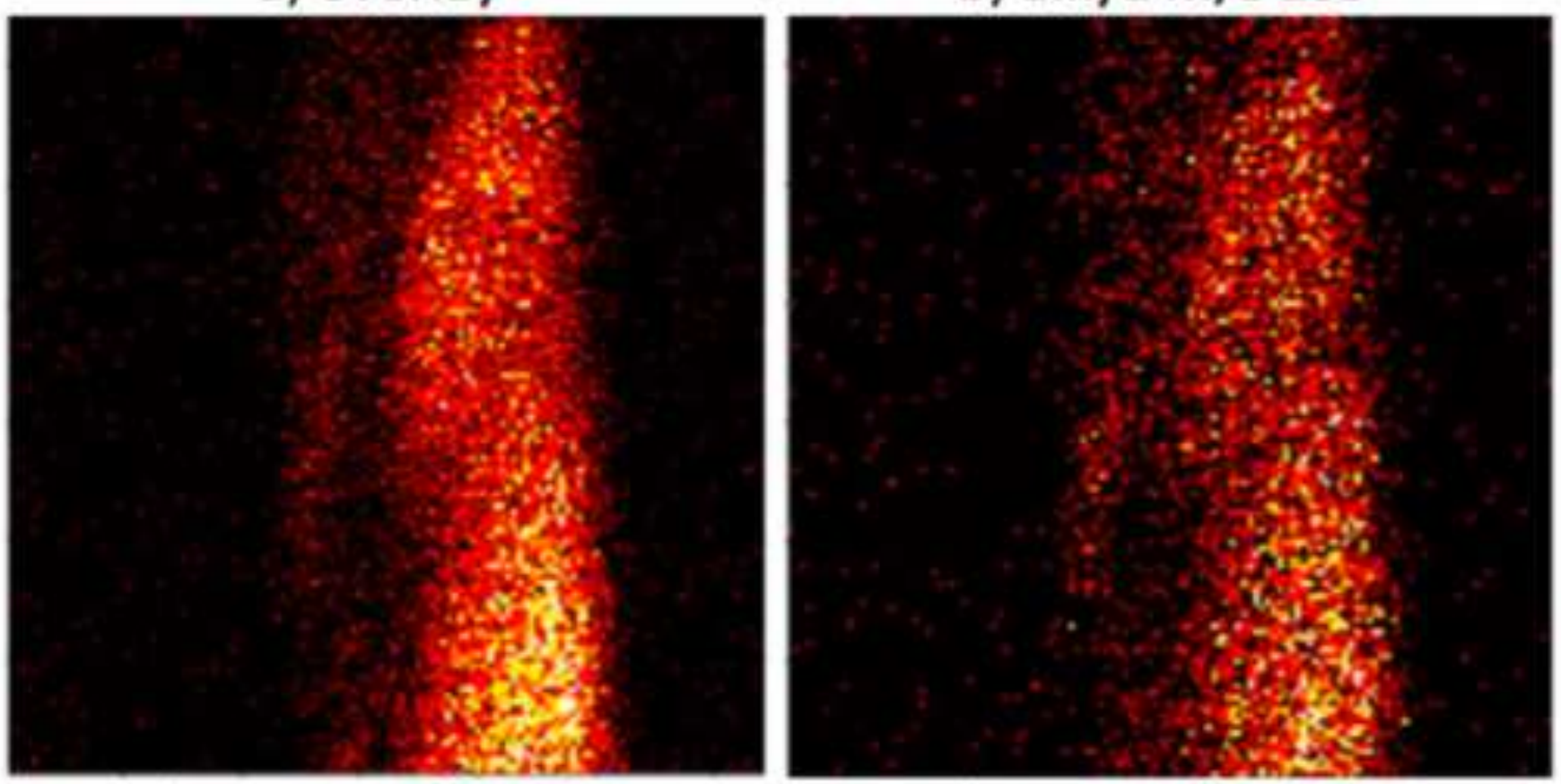

c) PB15:3 m/z 575.1

d) PV23 m/2 589.5 